\title{
'||||||||||||||||||||||||||||||||||||||||||||||||||||||||||||||||||||||||.
}

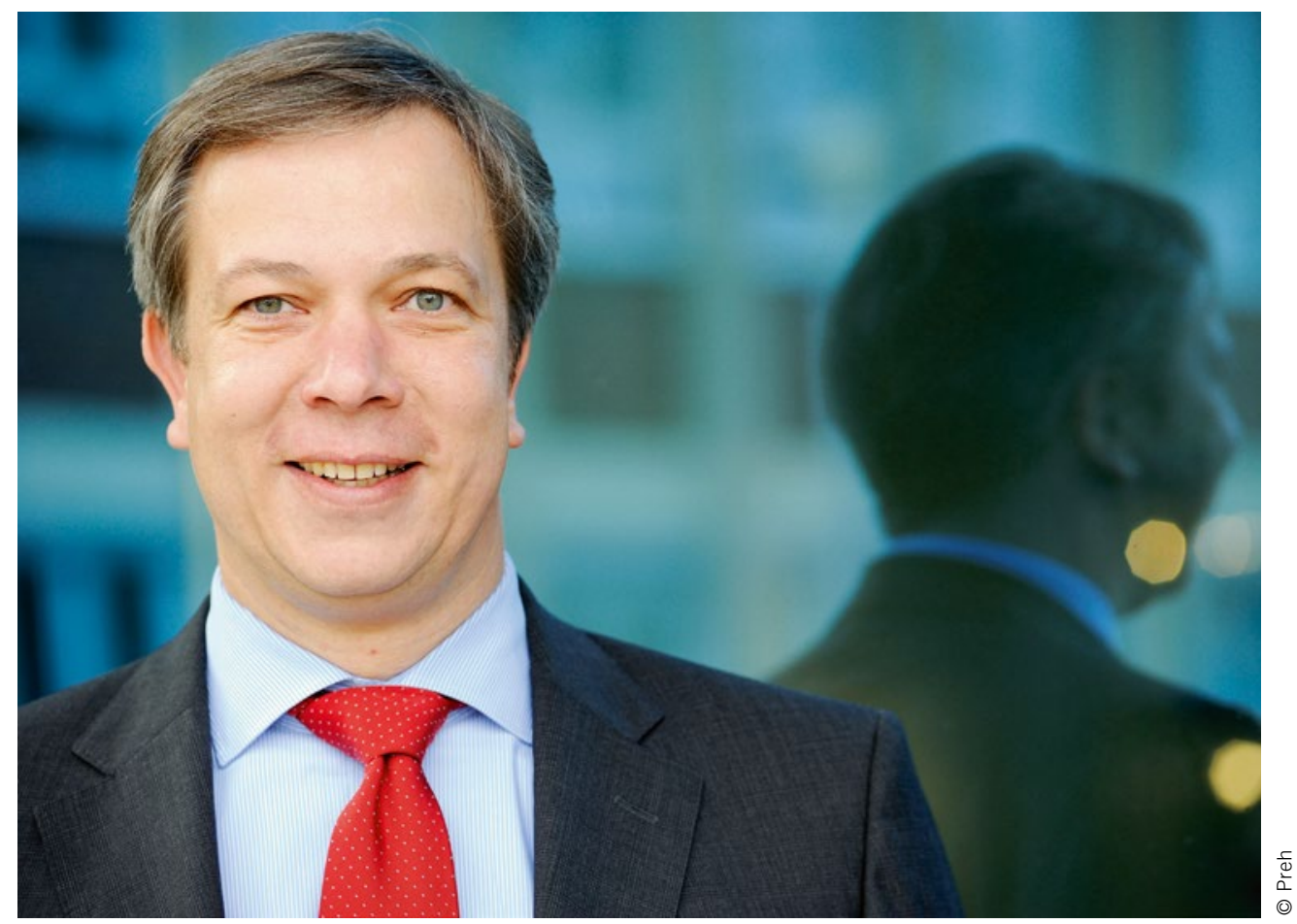

Dipl.-Wirt-Ing. (FH) MBA

Christoph Hummel

Geschäftsführer Vertrieb,

Marketing, Projektmanagement und E-Mobility, Preh GmbH (ab 1. Januar 2016 Vorsitzender der Geschäftsführung)

\section{Chinesisch-deutsches Win-Win}

Die IAA hat einmal mehr deutlich gemacht: Ein deutscher Zulieferer, der mehrheitlich von einem chinesischen Investor gehalten wird, stößt noch immer auf große Neugier. Dabei ist diese Konstellation für Preh und unseren chinesischen Gesellschafter Joyson längst zur Normalität geworden. 2011, im Jahr der Übernahme, gab es durchaus noch skeptische Fragen von Mitarbeitern, Kunden und Partnern. Heute funktioniert die deutsch-chinesische Zusammenarbeit gut.

Die Erfolgsfaktoren sind schnell ausgemacht: Joyson und Preh sind zwar beide im Fahrzeuginterieur „zu Hause“, verfügen aber über komplementäre Produktportfolios und Marktzugänge. Produktbeispiele für Preh sind unter anderem zentrale Bediensysteme, wie der iDrive Touch Controller für BMW oder das MMI all-in-touch für Audi. Joyson stellt im chinesischen Markt zum Beispiel Luftausströmer für Volkswagenund Skoda-Modelle her. So unterstützt uns Joyson bei der Markterschließung in China, während wir unserem Gesellschafter Hilfestellung in Europa und Nordamerika geben.

Typische Synergiethemen waren bei uns nie Thema. Im Gegenteil: Wir sind seit der Übernahme auch an unserem deutschen Stammsitz in Bad Neustadt an der Saale jedes Jahr im Schnitt um rund 100 Jobs gewachsen. Besonders positiv hat sich die Finanzkraft unseres chinesischen Investors ausgewirkt. Joyson investiert kräftig in alle Preh-Standorte. Jüngstes Beispiel: Für den Neubau unseres Forschungs- und
Entwicklungszentrums in Bad Neustadt steht ein Gesamtbetrag von 12,5 Millionen Euro zur Verfügung. Zuvor hatte unser Investor Jeff Wang bereits grünes Licht für den Neubau von Betriebsrestaurant und Ausbildungswerkstatt gegeben. Auch die ausländischen Preh-Standorte boomen: Unter der Ägide von Joyson sind neue Werke in China und Mexiko entstanden, während der Standort in Rumänien um das Doppelte wachsen wird und wir zwischenzeitlich auch in Portugal ein Ausbauprogramm auf den Weg bringen konnten.

Neben diesen harten Fakten gibt es aber auch viele menschliche Faktoren, die den Erfolg erklären. Jeff Wang ist ein Privatunternehmer, der - ähnlich wie das Preh-Management mittelständisch geprägt ist. Unsere Zusammenarbeit basiert auf einem hohen Maß an gegenseitigem Vertrauen, sodass wir als Preh-Geschäftsführung im operativen Geschäft weitgehend freie Hand haben. Offensichtlich wirkt das Miteinander von Preh und Joyson auch sehr positiv auf Chinesen, die in Deutschland leben. Inzwischen arbeiten bei uns in Bad Neustadt rund 30 chinesisch-stämmige Mitarbeiterinnen und Mitarbeiter, die für uns wertvolle sprachliche und kulturelle Brückenbauer nach China sind.

Unter dem Strich stehen Preh und Joyson für eine klassische Win-Win-Konstellation, die ich unter ähnlichen Voraussetzungen auch anderen Unternehmen ohne Wenn und Aber empfehlen kann. 